\title{
Diffuse Lewy body disease: clinical features in 15 cases
}

\author{
E JANE BYRNE, ${ }^{*}$ GRAHAM LENNOX, $\ddagger$ JAMES LOWE, \\ RICHARD B GODWIN-AUSTEN +
}

From the Departments of Health Care of the Elderly, ${ }^{*}$ Neurology, $\dagger$ and Pathology, $\ddagger$ Queen's Medical Centre, Nottingham, $U K$

SUMMARY Fifteen cases of diffuse Lewy body disease were diagnosed on pathological grounds during a single year in one health district. The range and frequency of clinical features contrast strikingly with previous reports. The majority of cases presented with classical levodopa-responsive Parkinson's disease either alone ( 6 cases) or with mild cognitive impairment ( 3 cases); the remaining 6 cases presented with cognitive impairment alone. In time almost all patients developed both dementia and Parkinsonism. The dementia was cortical in type, but unusual in that most (12 cases) showed dayto-day fluctuation in severity at some point in their illness. These findings suggest that diffuse Lewy body disease is not rare, and that it presents in a range of ways from dementia with subsequent Parkinsonism to Parkinson's disease with subsequent dementia. The latter mode of presentation suggests that it should be considered as a significant pathological substrate of dementia in Parkinson's disease.

Diffuse Lewy body disease is a neuropathological entity in which rounded eosinophilic inclusion bodies (Lewy bodies') are found within brainstem nuclei (in a manner identical to that which characterises idiopathic Parkinson's disease ${ }^{2}$ ) and throughout the cerebral cortex. Previous reports have described cases with progressive dementia, with or without psychiatric features, extrapyramidal syndromes, orthostatic hypotension and motor neuron disease..$^{3-32}$ These reports have generally described single or small numbers of cases and may therefore give an unrepresentative view of the clinical features.

In an effort to broaden this perspective we describe the 15 cases of diffuse Lewy body disease identified in a systematic survey of all brains referred to this institution from one health district during a single year.

\section{Materials amd methods}

All 216 brains received during the year 1 April 1985 to 31 March 1986 were examined for Lewy bodies. No attempt was made to influence routine referral patterns. Diffuse Lewy body disease was diagnosed where conventional haematoxylin and eosin (H\&E) stains revealed classical brainstem Lewy bodies in association with cortical Lewy bodies in both

Address for reprint requests: Dr G Lennox, Department of Neurology, Queen's Medical Centre, Nottingham NG7 2UH.

Received 12 August 1988 and in revised form 30 December 1988. Accepted 10 January 1989 limbic and neocortical regions (fig 1). All cases were also studied with solochrome-cyanin, thioflavine-S, the Cross modified Palmgren stain, ${ }^{33}$ and ubiquitin ${ }^{34}$ and neurofilament ${ }^{35}$ immunohistochemistry.

All cases identified spent time under the care of the Department of Health Care of the Elderly and most had therefore undergone prospective clinical evaluation as part of a continuing study of dementia in old age. The evaluation comprised detailed history and physical examination (with bedside tests of higher mental function supplemented in selected cases with the mental status questionnaire, Folstein Mini Mental State Examination and detailed psychometric testing including the Clifton Assessment Procedure for the Elderly and the Weschler Adult Intelligence Scale), routine biochemical, haematological and radiological investigations, and functional assessments by nurses, occupational therapists and physiotherapists. Assessment of the clinical features was based upon this evaluation, together with other behavioural information recorded in the hospital case notes and general practitioner records. Clinical and neuropathological assessments were made blind with respect to each other.

\section{Results}

Fifteen cases of diffuse Lewy body disease were identified from a total of 216 brains referred from within the Nottingham Health District (population 616,000 ) during one year. All fifteen cases came from within a subgroup of 57 cases known to suffer from dementia, an extrapyramidal syndrome or both. There was no evidence of geographical or occupational 


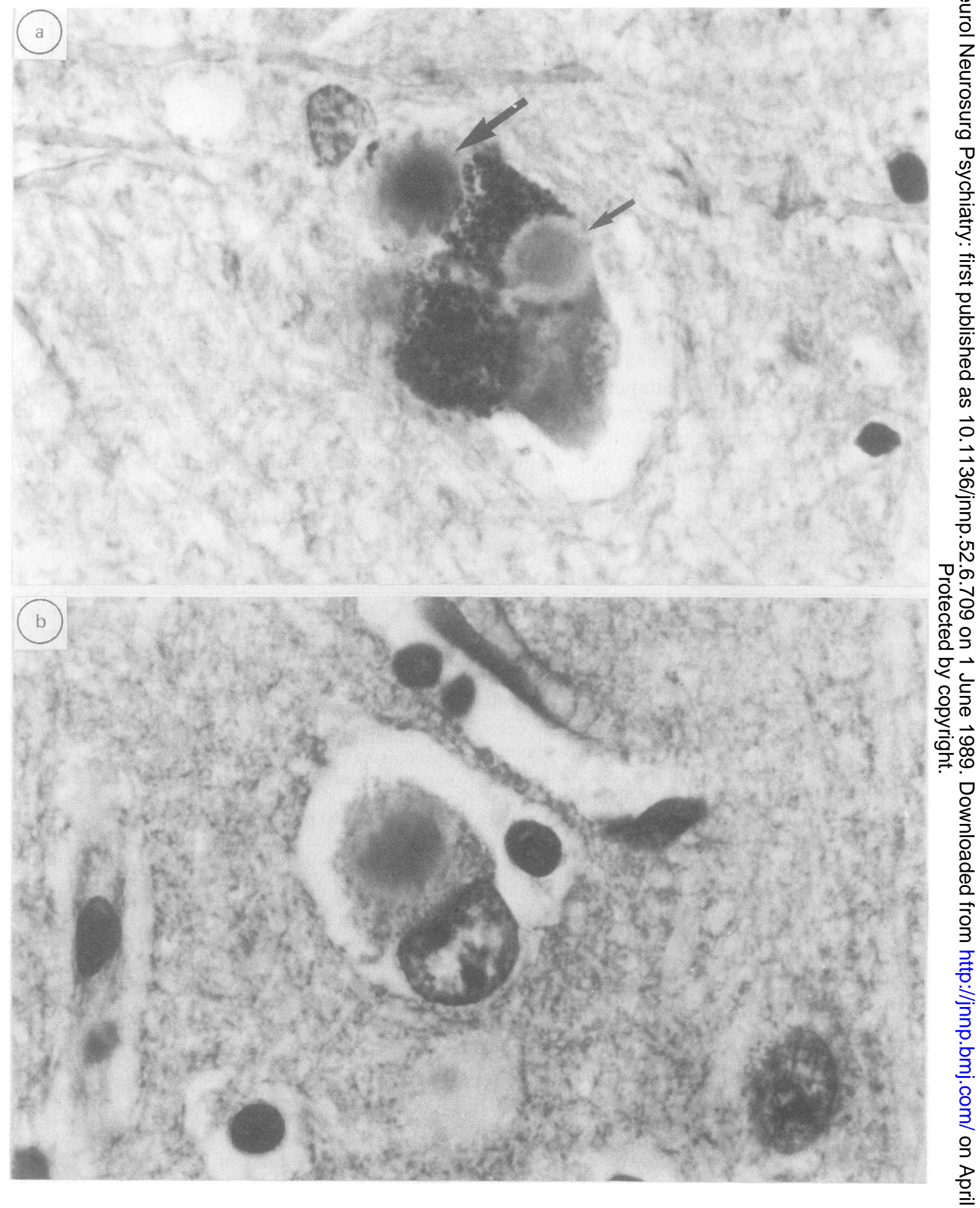

Fig 1 (a): Pigmented neuron in the substantia nigra containing a well-circumscribed brainstem Lewy body (small arrow) and $\mathcal{N}$ a less clearly defined Lewy body (large arrow). Haematoxylin and eosin, original magnification $\times 1430$. (b): Small neuron from the inferior temporal lobe containing a cortical Lewy body, which again is less clearly circumscribed. Haematoxylin and eosin, original magnification $\times 1430$. 
clustering of cases within the district to suggest a local environmental cause.

\section{Case reports}

The clinical features in this series differ in several important respects from those previously reported, and we therefore present brief individual case reports. These are summarised in table 1. The terms rigidity and tremor refer to the extrapyramidal forms unless otherwise stated. No case had a relevant family or past medical history. In all cases investigations for treatable causes of dementia and Parkinsonism were normal or negative unless otherwise stated.

Case 1 A Polish emigree developed problems of immobility in early 1984 at the age of 74 years; in particular she experienced difficulty in getting out of bed. In February 1985 she was admitted to hospital following a fall. She had moderate generalised rigidity and bradykinesia, mild bilateral tremor, a flexed posture and a shuffling gait; she was also disorientated with poor recollection of recent events. Treatment with levodopa/carbidopa produced improvement in her motor signs but her mental state continued to deteriorate. By August 1985 she showed global cognitive impairment with, for example, disorientation in time and place, gross impairment of immediate and distant recall, and nominal dysphasia. She became intermittently agitated and disruptive, and required sedation with phenothiazines with consequent deterioration in her motor state. By October 1985 her periods of agitation were alternating with periods of drowsiness which were unrelated to sedatives or intercurrent medical illness. In March 1986 she died suddenly of massive pulmonary embolism.

Case 2 A retired coach driver developed classical idiopathic Parkinson's disease in August 1984 at the age of 82 years, with bilateral tremor and excessive sweating. By January 1985 the tremor was disabling and he had developed hypomimia, and mild bradykinesia. Treatment with levodopa/carbidopa produced considerable benefit, but also epigastric discomfort and in October 1985 he changed to orphenadrine. By November 1985 he had developed postural instability; he was depressed, irritable and mildly forgetful but otherwise cognitively intact. He was admitted to hospital in January 1986 after a series of falls; he was drowsy and disorientated and had mild generalised rigidity. He also had evidence of an acute exacerbation of chronic bronchitis; this worsened despite treatment with antibiotics and he died one week after admission.

Case 3 A university lecturer developed classical idiopathic Parkinson's disease in November 1981 at the age of 61 years, with gradual onset of tremor, bradykinesis and gait disturbance. There was no disturbance of intellectual function (fig 2). His symptoms responded well to treatment with benzhexol and amantadine. During the summer of 1983 he rapidly developed global cognitive impairment which fluctuated markedly in severity from day to day. There was prominent jargon dysphasia with spontaneous speech dominated by meandering scientific and statistical phrases. Drug withdrawal produced deterioration in both mental and motor function; bromocriptine, amantadine and levodopa/carbidopa were subsequently introduced, producing motor but not mental improvement. By November 1984 he needed help with everyday activities; he had great difficulty in dressing (due to dyspraxia rather than bradykinesia), took up to two hours to eat his meals and frequently wandered at night. He became emotionally labile and began to micturate in inappropriate situations. His cognitive function continued to deteriorate in a fluctuating fashion, culminating in severe dementia. He died from a perforated sigmoid volvulus in February 1986.

Case 4 A woman developed classical idiopathic Parkinson's disease in 1980 at the age of 74 years, with rigidity and postural instability with retropulsion. She responded well to treatment with levodopa/benserazide. In 1981 she developed frequency of micturition treated briefly with propantheline. In 1983 she was increasingly troubled by falls and had developed persistent moderate impairment of memory; at times this was accompanied by symptoms of depression, but

Table 1 Clinical features

\begin{tabular}{|c|c|c|c|c|c|c|c|c|c|c|c|c|c|c|c|c|}
\hline \multirow[b]{2}{*}{$\begin{array}{l}\text { Case } \\
\text { no }\end{array}$} & \multirow{2}{*}{$\begin{array}{l}\text { Age } \\
\text { at } \\
\text { onset } \\
(y r)\end{array}$} & \multirow[b]{2}{*}{ Sex } & \multirow[b]{2}{*}{$\begin{array}{l}\text { Dur } \\
(y r)\end{array}$} & \multirow[b]{2}{*}{ Presentation } & \multicolumn{6}{|c|}{ Motor features } & \multicolumn{6}{|c|}{ Neuropsychiatric features } \\
\hline & & & & & Rig & $B k$ & $\operatorname{Tr}$ & Gait & Post & $\begin{array}{l}\text { Levodopa } \\
\text { response }\end{array}$ & Mem & Lang & Prax & Calc & Psych & $\begin{array}{l}\text { Fluct } \\
\text { cogn }\end{array}$ \\
\hline 1 & 74 & $\mathbf{F}$ & 2 & Parkinsonism & + & + & + & + & + & Definite & + & + & + & + & & + \\
\hline 2 & 82 & $\mathbf{M}$ & $\overline{3}$ & Parkinsonism & + & + & + & + & & Definite & + & - & - & - & D & - \\
\hline 3 & 58 & $\mathbf{M}$ & 5 & Parkinsonism & + & + & + & + & + & Definite & + & + & + & & & + \\
\hline 4 & 74 & $\mathbf{F}$ & 5 & Parkinsonism & + & + & + & + & & Definite & + & & & & D & - \\
\hline 5 & 68 & $\mathbf{F}$ & 19 & Parkinsonism & + & + & + & + & + & Definite & + & & & & D & + \\
\hline 6 & 72 & $\mathbf{F}$ & 8 & Parkinsonism & + & + & + & + & + & Definite & + & & & + & & + \\
\hline 7 & 73 & $\mathbf{M}$ & 3 & Both & + & + & + & + & + & No trial & + & & & & & + \\
\hline 8 & 62 & M & 4 & Both & + & + & + & + & + & Definite & + & - & + & + & $\mathbf{H}$ & + \\
\hline 9 & 75 & $\mathbf{M}$ & 5 & Both & + & + & - & + & & Probable & + & & & & & + \\
\hline 10 & 83 & $\mathrm{~F}$ & 3 & Dementia & - & - & - & - & + & No trial & + & + & + & + & & + \\
\hline 11 & 65 & $\mathbf{F}$ & 2 & Dementia & + & - & - & + & + & No trial & + & + & + & + & $\mathbf{H}$ & + \\
\hline 12 & 73 & $\mathbf{M}$ & 8 & Dementia & + & + & - & + & + & Definite & + & + & + & + & & + \\
\hline 13 & 71 & $\mathbf{F}$ & 6 & Dementia & + & & + & + & - & Definite & + & + & + & + & $\mathbf{H}$ & + \\
\hline 14 & 70 & $\mathbf{F}$ & 7 & Dementia & + & - & + & + & + & Definite & + & + & + & + & $\mathbf{H}$ & + \\
\hline 15 & 83 & $\mathbf{M}$ & 3 & Dementia & - & - & - & + & - & No trial & + & + & & + & & - \\
\hline
\end{tabular}

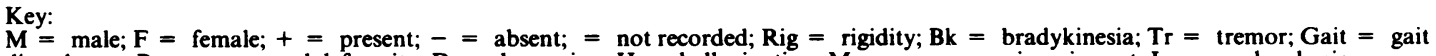
disturbance; Post $=$ postural deformity; $\mathrm{D}=$ depression; $\mathrm{H}=$ hallucination; $\mathrm{Mem}=$ memory impairment; Lang $=$ dysphasia; Prax $=$ dyspraxia $;$ Calc $=$ dyscalculia; Psych $=$ psychiatric symptoms; Fluct cogn $=$ fluctuations in cognition. 

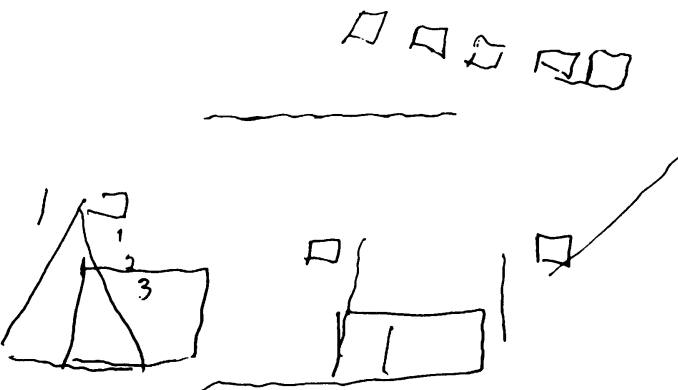

Fig 2 An example of constructional dyspraxia (Case 3). The attempt to draw a house has resulted in an "exploded" diagram; the windows and roof tiles can be seen alongside and above the house respectively, while the numerals adjacent to the roof gable represent perseveration of a previous (unsuccessful) attempt to draw a clock.

there was no cognitive improvement on treatment with antidepressants. By 1986 she had developed a bilateral tremor. She fell fracturing her left hip in February 1986; operative repair and rehabilitation were initially successful but she was readmitted in March 1986 with bronchopneumonia and died.

Case 5 A woman developed classical idiopathic Parkinson's disease in 1966 at the age of 68 years, manifested predominantly as left-sided tremor and bradykinesia. In 1969 she underwent right cryogenic thalamotomy; the procedure was complicated by a transient mild left hemiparesis and acute confusional state but produced substantial improvement in her motor symptoms and signs. By 1971 she had developed resting tremor of the right upper limb, and had become intermittently forgetful; treatment with levodopa was commenced with initial motor improvement, but by 1976 her motor state had deteriorated such that she was unable to walk without assistance. In 1978 she was admitted for continuing care. She had mild global cognitive impairment with episodic exacerbation which was not explained by routine investigations, together with marked bradykinesia, generalised rigidity and blepharospasm. Her treatment was changed to levodopa/carbidopa and mianserin with some motor but no cognitive improvement. In 1979 she developed disinhibited and inappropriate behaviour. Over the next six years her mental state continued to fluctuate whilst her mobility gradually deteriorated. Her antiparkinsonian treatment was withdrawn on several occasions because of her recurrent confusional states; on each occasion this produced no change in mental state but marked motor deterioration. By 1984 she had moderate global dementia, had adopted a flexed posture and required the assistance of two nurses to transfer from bed to chair. In August 1985 she developed bronchopneumonia and died.

Case 6 A woman developed classical idiopathic Parkinson's disease in early 1978 at the age of 72 years, with hypomimia, moderate generalised rigidity, predominantly right sided tremor, and slowness of gait. She responded to treatment with benzhexol and levodopa/benserazide. By November 1978 she had developed impairment of short term memory and severe dyscalculia. Benzhexol was withdrawn without any cognitive improvement. By August 1984 she had developed bradykinesia and a tendency to retropulsion; her cognitive impairment had become global and tended to fluctuate with periods of lethargy and withdrawal which were not relieved by mianserin. In March 1985 she was admitted having fallen and fractured her right hip. She was uncommunicative, profoundly demented and had developed flexion contractures of the lower limbs. She died suddenly in November 1985 from severe coronary atherosclerosis.

Case 7 A man developed symptoms and signs typical of idiopathic Parkinson's disease early in 1983 at the age of 73 years, with mild bilateral tremor and gait disturbance, together with mild cognitive impairment. Investigations revealed a macrocytic anaemia with folate and vitamin B12 deficiency due to late-onset coeliac disease but his mental and motor impairment did not improve following correction of these abnormalities. By May 1985 he had developed hypomimia, generalised rigidity, micrographia and postural instability; his cognitive function fluctuated with periods of near-normality alternating with episodes of marked confusion for which no cause was found. By November 1985 he had persistent moderate global cognitive impairment; he was admitted to hospital and died in January 1986 of pulmonary embolism.

Case 8 This case has been described in detail elsewhere. ${ }^{4}$ In summary, a 62 year old retired gravestone cleaner developed symptoms and signs typical of idiopathic Parkinson's disease with bradykinesia, rigidity, festinant gait disturbance and abnormality of posture; shortly afterwards he developed global cognitive impairment which fluctuated in severity from day to day. The motor features responded to treatment with levodopa/carbidopa, but the cognitive features did not; he became profoundly demented, increasingly dependent on nursing care and died of bronchopneumonia four years after the onset of symptoms.

Case 9 A retired railwayman developed forgetfulness and fluctuating confusion in 1980 at the age of 75 years, together? with motor difficulties, with an unsteady, shuffling gait and frequent falls. By June 1982 he was confused regarding recent events and had hypomimia, moderate generalised rigidity and bradykinesia, a festinant gait, and loss of postural reflexes. He was treated with levodopa/benserazide with some motor but no cognitive improvement. In August 1983 he fell fracturing his left hip; despite operative repair he gradually became increasingly immobile to the point where two nurses were needed to turn him in bed. His mental state also continued to deteriorate in a fluctuating fashion, with recurrent exacerbations of his intellectual impairment. On some occasions these exacerbations were associated with evidence of urinary, respiratory or gastrointestinal infection, but in general their aetiology remained obscure. In February 1984 he developed pemphigoid which was successfully suppressed with prednisolone. By March 1985 he was severely demented; he developed bronchopneumonia and died.

Case 10 A woman developed gradually progressive cognitive impairment in late 1983 at the age of 83 years. By 1985 she required constant supervision and had become intermittently hostile and suspicious. She had an abnormal posture with cervical flexion and lumbar extension, but no other extrapyramidal signs. Her condition initially fluctuated markedly, such that at times she was able to hold a conversation, albeit with some expressive dysphasia, whilst 
on other occasions she was mute and unable to stand without assistance. Investigations revealed no cause for these fluctuations. She became profoundly demented and in October 1985 fell fracturing her right wrist; she subsequently developed bronchopneumonia and died.

Case 11 A woman developed neuropsychiatric symptoms in 1983 at the age of 65 years, with intellectual deterioration, paranoid delusions and auditory hallucinations; for example, she had difficulty in recognising her children, ate dog food, accused her family of plotting against her, and heard strange men talking in her flat. She became restless and distractable, with marked fluctuation in her mental state: CAPE and MMS scores varied by more than $50 \%$ from one day to the next. During 1984 there was rapid deterioration, with first nominal and then jargon dysphasia and constructional dyspraxia developing over a period of six weeks. She developed a spastic tetraparesis with axial rigidity and severe cervical flexion. A diagnosis of Creutzfeldt-Jakob disease was considered, and serial electroencephalography showed triphasic waves posteriorly consistent with this diagnosis, but there was no ataxia or myoclonus and her condition stabilised from September 1984 until September 1985 when she developed bronchopneumonia and died.

Case 12 This case has also been described in detail elsewhere. ${ }^{4}$ In summary, a pharmaceutical packer became forgetful at the age of 75 years and subsequently developed global cognitive impairment and a Parkinsonian syndrome with bradykinesia, rigidity, tremor, gait disturbance and abnormality of posture. There was motor but not cognitive improvement on treatment with levodopa/carbidopa; he became increasingly immobile and demented and died of bronchopneumonia eight years after the onset of symptoms. Case 13 A woman looked after a disabled lodger until April 1979 when, at the age of 71 years, she developed neuropsychiatric symptoms. She became forgetful, neglected household duties, and complained of visual hallucinations such as seeing animals in the house. By the end of 1979 she had severe but fluctuating global cognitive impairment (with amnesia, constructional dyspraxia and expressive dysphasia), ideas of reference and paranoid delusions (for example, attributing her symptoms to the malign influence of the television set, believing that she was being followed and that people were stealing her money). She was treated initially with chlormethiazole and in June 1980 with haloperidol. In October 1980 she developed a Parkinsonian syndrome, with hypomimia, tremor, rigidity and sialorrhoea, which persisted despite withdrawal of haloperidol. By 1982 her Parkinsonian syndrome had worsened to the point where she required assistance with all everyday activities. Levodopa/carbidopa was introduced, producing initial motor improvement but increased agitation. Her condition steadily deteriorated and by 1985 she had become mute, rigid, immobile and incontinent; she developed bronchopneumonia and died.

Case 14 A woman developed slowly progressive memory impairment in 1979 at the age of 70 years. In early 1981 she developed bilateral tremor which responded to treatment with benzhexol. In August 1981 her cognitive impairment worsened acutely, with auditory and visual hallucinations. No underlying cause was found, and episodic exacerbations of her cognitive impairment persisted over the next three years despite withdrawal of anticholinergic treatment. Her Parkinsonian syndrome worsened gradually and by 1984 she had severe tremor, rigidity, gait disturbance and marked flexed postural deformity. She was treated with levodopa/ carbidopa with considerable motor improvement. Her mental and motor condition continued to deteriorate, however, and by 1985 she was mute and immobile. She developed pressure sores and bronchopneumonia, and died in December 1985.

Case 15 This man began to experience forgetfulness in 1983 at the age of 83 years. He developed a series of overvalued ideas, attributing his memory disturbance to non-steroidal anti-inflammatory treatment and ruminating about an imagined abnormality of his testicles. His speech became rambling and incomprehensible. He was admitted to hospital in 1986 following a fall. He was agitated with profound global cognitive impairment, including a marked expressive and receptive dysphasia, and a shuffling gait, requiring the assistance of two people to walk. He received sedation with thioridazine. He died suddenly four weeks after admission from myocardial infarction.

\section{Neuropathological features}

The neuropathological features will be described in detail elsewhere. In brief, all cases showed cell loss in the substantia nigra, with classical Lewy bodies in remaining neurons. These changes were indistinguishable from those which characterise uncomplicated idiopathic Parkinson's disease. All cases also showed large numbers of Lewy bodies in the cerebral cortex, most frequently in small neurons within the deeper layers of the temporal, anterior cingulate, insular, entorhinal and frontal cortices. These are the features of diffuse Lewy body disease.

Four cases (Cases 4, 13, 14 and 15) also showed sufficient numbers of neurofibrillary tangles in the hippocampus and temporal cortex to suggest a second diagnosis of Alzheimer's disease. No other neuropathological diagnoses were made; in particular there was no evidence of Pick's disease, Hallervorden-Spatz disease, von Economo's encephalitis, or significant cerebrovascular disease.

\section{Clinical features}

The mean age at onset of symptoms was 72 years (range 5883 years) and the mean duration of illness was 5.5 years (range 2-19 years).

Parkinsonian features Six $(40 \%)$ cases presented with symptoms and signs which were typical of and indistinguishable from those of idiopathic Parkinson's disease. All six had extrapyramidal rigidity, bradykinesia, rest tremor and classical gait disturbance; four also had a markedly flexed posture. All of these cases responded well to treatment with levodopa and deteriorated abruptly whenever it was withdrawn. Cognitive impairment developed an average of four years (range 1-14 years) after the onset of motor symptoms.

A further three $(20 \%)$ cases had similar Parkinsonian features together with mild cognitive impairment either at or shortly after presentation. Of these, one case was definitely levodopa-responsive; one was probably levodopa-responsive in that motor improvement occurred on commencing treatment but this coincided with a period of intensive rehabilitation; one did not receive levodopa.

The other six $(\mathbf{4 0} \%)$ cases showed motor features later in their illnesses (average interval four years; range 1-6 years). 
Four developed syndromes which were Parkinsonian in that they showed gait disturbance which was described as "festinant", "shuffling" or "Parkinsonian", together with two or three of the four other cardinal signs of Parkinson's disease (that is, extrapyramidal rigidity, bradykinesia, rest tremor and flexed postural deformity). Three of these patients received and responded to treatment with levodopa. The remaining two cases showed flexed postural deformity and gait disturbance alone.

Neuropsychiatric features Six $(40 \%)$ cases presented with neuropsychiatric disturbance; of these six cases, one each presented with memory impairment alone, memory impairment with overvalued ideas, dementia alone, dementia with paranoid ideas, dementia with auditory and visual hallucination, and dementia with both paranoid delusions and hallucination. All 15 cases eventually showed some neuropsychiatric disturbance; all 15 had impairment of memory which was mild in Case 2 (and associated with depression) and moderate to very severe in the other 14 cases. In these 14 cases, where detailed neuropsychological assessment was possible there was clear evidence of cortical deficits including dysphasia (eight cases), dyscalculia (10 cases) and visuospatial, constructional and ideomotor dyspraxia (nine cases); the remaining cases were too obtunded at the time of clinical evaluation to allow detailed assessment but in all cases disturbance of cortical functions such as language and praxis could be inferred from behavioural observations.

In twelve $(80 \%)$ cases there was striking fluctuation in cognitive impairment. For example, some patients would be muddled one day and alert the next. The fluctuations were usually diagnosed as acute confusional states, but in general investigations revealed no underlying cause. Cognitive fluctuations were recorded in drug-naive patients and could not be attributed to changes in levodopa or other treatment; in patients receiving levodopa cognitive fluctuations were not accompanied by fluctuations in motor state, making it unlikely that they were related to variations in levodopa levels (which, in any case, tend to occur over hours rather than days). ${ }^{36}$

Three patients, all from the group presenting with Parkinson's disease, showed evidence of depression. Five patients, all from the groups presenting with dementia, had auditory or visual hallucinations or delusions with paranoid content.

\section{Discussion}

The literature on diffuse Lewy body disease has grown steadily since the first two cases were described by Okazaki et al in $1961 .{ }^{25}$ By the end of 198744 cases had been reported with individual clinical details, ${ }^{4-27} 29-32$ whilst a further seven cases had been summarised in abstracts. ${ }^{328}$ There are at least a further 16 case reports in the literature where diffuse Lewy body disease is suspected but not definitely diagnosed, ${ }^{32}{ }^{37}$ this group of cases is not included in the analysis below. The present report describes the clinical features of a further 15 cases showing the neuropathological features of diffuse Lewy body disease.

\section{Incidence of diffuse Lewy body disease}

The increasing frequency of reports of diffuse Lewy body disease almost certainly reflects improving $\stackrel{\equiv}{\mathrm{O}}$ neuropathological recognition rather than a true $Z$ increase in incidence. It is a condition that is easily $\stackrel{\mathbb{C}}{\subseteq}$ overlooked, unless specifically sought. By the sys- 응 tematic use of routine H\&E stains we have identified 15 cases from a limited population in a single year. $A_{0}^{\widehat{C}}$ retrospective post-mortem series such as this is inevitably subject to bias; in particular, post-mortem examinations are more likely to be requested on hospital inpatients (who tend to be elderly and heavily dependent) and the clinically puzzling. The series is $\Rightarrow$ especially likely to underestimate of the incidence of $\stackrel{\oplus}{?}$ diffuse Lewy body disease in young patients who are? often cared for at home by their fit spouses. Despite $\frac{\overline{\bar{O}}}{\mathrm{D}}$ these limitations, the fact that 15 cases of diffuse Lewy $\frac{\bar{c}}{\sigma}$ body disease were identified within a limited popula- $\Omega$ tion in a single year suggests that the disease is not as rare as the literature would suggest.

\section{Range of clinical features}

This study documents for the first time the clinical features of a large and systematic series of cases of $\bar{z}$ diffuse Lewy body disease. None of the clinical on features described here is previously unreported, but many of them were much more common than on would expect from the literature (table 2). To som 8 extent these differences may reflect the brevity of mang $\frac{1}{3}$ previous reports (for example, 11 of the 51 reports give no information regarding mode of presentation).

\section{Presentation with Parkinsonian features}

Few of the previously reported cases of diffuse Lew 1 body disease presented with symptoms or signs of Parkinson's disease. Ikeda et al ${ }^{11}$ described a 30 year old man who presented with slight gait disturbance, bradykinesia and hypomimia, which worsened over six years to include generalised rigidity and slight $\frac{\mathscr{O}}{\triangleright}$ tremor; there was a remarkable response to levodopa $\cong$ but the patient died suddenly aged 38 . Kono et al ${ }^{15} \overrightarrow{\vec{O}}$ described a 55 year old woman who presented with $\exists$ dizziness, hand tremor and bradykinesia, and who subsequently developed rigidity, orthostatic hypotension and dementia; no trial of levodopa is recorded. Sima et $a l^{29}$ described a 72 year old woman who 긍 presented with Parkinsonism; she subsequently developed a spastic tetraparesis, emotional lability with intermittent aggression, bradykinesia and $\delta$ rigidity; levodopa produced little benefit. Finally Gibb et $a l^{10}$ described a 33 year old woman who presented 은 with depression and irritability but within a month developed left-sided tremor, rigidity and bradykinesia which was levodopa-responsive; she subsequently developed flexed posture, shuffling gait and pro- $\sigma$ gressive dementia with paranoid delusions and $\tilde{O}$ auditory hallucinations. These four cases constitute $\underset{\omega}{\mathrm{E}}$ $8 \%$ of those in the previous literature. This contrasts

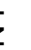


strikingly with the findings in the present series, where the majority of patients presented with Parkinson's disease, either alone $(40 \%)$ or with mild cognitive impairment $(20 \%)$.

\section{Subsequent development of Parkinsonian syndrome} In the literature, most cases of diffuse Lewy body disease eventually develop both dementia and a Parkinsonian syndrome, although in many instances ( $48 \%$ of cases) the latter was limited to only one or two of the cardinal features of Parkinson's disease whilst 11 cases $(22 \%)$ had dementia without motor features (table 2). Again this contrasts strikingly with the present series where all 15 cases developed both cognitive and motor features, and where the motor features were minor in only two $(13 \%)$.

In general the clinical features of these cases were consistent with those found in the subgroup of patients with Parkinson's disease who are elderly and demented, which we have elsewhere termed Type II Parkinson's disease. ${ }^{38}$

\section{Levodopa response}

It is increasingly recognised that patients with an akinetic-rigid Parkinsonian syndrome who do not respond to levodopa may have illnesses other than idiopathic Parkinson's disease. ${ }^{39}$ Only three $(6 \%)$

Table 2 Clinical features of present series compared with previous reports ${ }^{3-32}$

\begin{tabular}{|c|c|c|}
\hline $\begin{array}{l}\text { Clinical } \\
\text { feature }\end{array}$ & $\begin{array}{l}\text { Present series } \\
\text { Number of } \\
\text { cases }(\%)\end{array}$ & $\begin{array}{l}\text { Previous reports } \\
\text { Number of } \\
\text { cases }(\%)\end{array}$ \\
\hline $\begin{array}{l}\text { A. At presentation: } \\
\text { Parkinsonism alone } \\
\text { Parkinsonism \& n/psych } \\
\text { Neuropsychiatric alone } \\
\text { Other } \\
\text { Unspecified }\end{array}$ & $\begin{array}{l}6(40) \\
3(20) \\
6(40) \\
0 \\
0\end{array}$ & $\begin{array}{c}3(6) \\
1(2) \\
34(67) \\
2(4) \\
11(22)\end{array}$ \\
\hline & 15 & 51 \\
\hline $\begin{array}{l}\text { B. Subsequently: } \\
\text { Parkinsonism without } \\
\text { dementia }\end{array}$ & 0 & $1(2)$ \\
\hline $\begin{array}{l}\text { Dementia without } \\
\text { Parkinsonism }\end{array}$ & 0 & $10(22)$ \\
\hline $\begin{array}{l}\text { Dementia with gait } \\
\text { disturbance or flexed } \\
\text { posture alone }\end{array}$ & $2(13)$ & $4(8)$ \\
\hline $\begin{array}{l}\text { Dementia with tremor, } \\
\text { rigidity, or } \\
\text { bradykinesia alone }\end{array}$ & 0 & $7(14)$ \\
\hline $\begin{array}{l}\text { Dementia with two of the } \\
\text { above }\end{array}$ & 0 & $13(26)$ \\
\hline $\begin{array}{l}\text { Dementia with three of } \\
\text { the above }\end{array}$ & $3(20)$ & $8(16)$ \\
\hline $\begin{array}{l}\text { Dementia with four or } \\
\text { more }\end{array}$ & $10(67)$ & $3(6)$ \\
\hline $\begin{array}{l}\text { Dementia with unspecified } \\
\text { Parkinsonism }\end{array}$ & 0 & $5(10)$ \\
\hline C. Levodopa-response & $\begin{array}{l}15 \\
11(75)\end{array}$ & $\begin{array}{l}51 \\
3(6)\end{array}$ \\
\hline
\end{tabular}

previous reports of diffuse Lewy body disease described a response to levodopa; these reports are those of Ikeda ${ }^{11}$ and Gibb $^{10}$ cited above, and that of Yoshimura $^{31}$ who described a 60 year old man who presented with symptoms of orthostatic hypotension; he subsequently developed akinesia and rigidity which responded transiently to levodopa, and dementia which did not. In general previous reports do not mention attempts at treatment, but those of Mitsuyama $^{24}$ and Sima et al $^{29}$ describe two patients who received little or no benefit from levodopa. However, the present series gives a markedly different impression. Eleven patients received levodopa; ten showed definite and one probable benefit, suggesting a high level of levodopa-responsiveness in this group.

\section{Fluctuation in cognitive state}

Although unexplained, fluctuation in the severity of cognitive impairment is the only early clinical feature in this series which distinguishes the dementia associated with diffuse Lewy body disease from other forms of cortical dementia. It has been reported before by Forno et al, ${ }^{9}$ Ikeda et al, ${ }^{12}$ Clark et al ${ }^{5}$ and Gibb et $a l^{10}$ (two cases), that is, in $10 \%$ of reported cases. This contrasts with the $12(80 \%)$ cases in this series who showed marked cognitive fluctuation at some point in their illnesses. This disparity may simply reflect the paucity of clinical detail offered in the majority of case reports. A similar phenomenon is noted by Woodard ${ }^{40}$ amongst the 27 cases of neuropsychiatric illness with brainstem Lewy bodies which he identified in a retrospective study of 400 brains from mental hospitals, although he does not comment on the presence or absence of cortical Lewy bodies in these cases.

Regardless of the mode of presentation, the late features of diffuse Lewy body disease are dementia and Parkinsonism. This, together with the fluctuating cognitive impairment, frequently led to an erroneous clinical diagnosis of multi-infarct dementia in this series. Multi-infarct dementia is, however, probably an unusual complication of idiopathic Parkinson's disease; vascular disease in general is less common in Parkinsonians than the general population as judged by a case-control study (RB Godwin-Austen and G Stern, unpublished observations). Parkinsonian features are also commonly found in other forms of cortical dementia including that judged clinically to be senile dementia of the Alzheimer type. ${ }^{41}$ Recent evidence suggests that in these cases the Parkinsonian features may in fact be attributable to coexistent brainstem Lewy body pathology; ${ }^{42}$ clearly a large prospective clinicopathological study is required to elucidate the nosology of these "extrapyramidal dementias". The importance of such a study has been emphasised by the recent observation that the sub- 
group of dementia patients with Parkinsonian features have a poorer prognosis than patients with dementia alone. $^{43}$

\section{Neuropsychiatric aspects}

The psychiatric features of diffuse Lewy body disease have received increasing attention in recent case reports. ${ }^{710}$ In this series the majority of patients $(53 \%)$ experienced psychiatric disorder. Depression, which is thought to be common in Parkinson's disease, occurred in three cases and responded to conventional tricyclic antidepressant treatment. Auditory and visual hallucinations, and paranoid ideation (often accompanied by aggressive behaviour) occurred in a further five cases; it was more difficult to manage, because conventional dopamine antagonist treatment produced marked deterioration in extrapyramidal function.

\section{Conclusions}

Although a retrospective survey of this type cannot give accurate information regarding prevalence, it suggests that diffuse Lewy body disease is not rare. It confirms that diffuse Lewy body disease presents in a variety of ways, with a spectrum ranging from a Parkinsonian syndrome with subsequent dementia to dementia with a subsequent Parkinsonian syndrome. It suggests that the former mode of presentation, indistinguishable from idiopathic Parkinson's disease in clinical features and levodopa-response, may be far commoner than has previously been realised, and thus that diffuse Lewy body disease may be a significant cause of dementia in Parkinson's disease. It shows that the latter mode of presentation, with "extrapyramidal dementia", is also common in diffuse Lewy body disease; the disease must be considered in the differential diagnosis of such cases, especially in assessing differences in prognosis in prospective clinical studies of dementia. Finally, it shows that the dementia of diffuse Lewy body disease generally shows cortical features, and may fluctuate in severity from day-to-day.

We hope that these observations will stimulate further research into this poorly-understood pathological entity. A prospective clinicopathological study, conducted by neuropathologists familiar with the appearances of diffuse Lewy body disease, is now required to establish its place amongst the other, more established, causes of dementia with extrapyramidal features and in particular to determine the frequency with which it forms the pathological basis of the common and important problem of dementia in Parkinson's disease.

This research was supported in part by the Parkinson's
Disease Society, The Stanhope Trust and The Special Trustees of the Nottingham University Hospitals. The authors thank the many doctors who allowed access to their records, the pathologists who referred brains, Prof John Mayer and Dr Michael Landon for providing ubiquitin antibody, $\mathrm{Mr}$ David McQuire and $\mathrm{Mr}$ Ken Morrell for technical assistance, and Mr Bill Brackenbury for photomicrography.

\section{References}

1 Lewy FH. Paralysis agitans. I: Pathologische anatomie. In Lewondowsky M, ed. Handbuch der Neurologie III. Berlin: Springer. 1912:920-33.

2 Oppenheimer DR. Diseases of the basal ganglia, cerebellum and motor neuron. In: Hume Adams J, Corsellis JAN, Duchen LW, eds. Greenfield's Neuropathology. London: Arnold, 1984 699-747.

3 Burkhardt C, Filley CM, Kleinschmidt-DeMasters BK, et al. Diffuse Lewy body disease and progressive dementia. Neurology 1987;37(Suppl. 1):331.

4 Byrne EJ, Lowe J, Godwin-Austen RB, et al. Dementia and Parkinson's disease associated with diffuse cortical lewy bodies. Lancet 1987;1:501.

5 Clark AW, White CL, Manz HJ, et al. Primary degenerative dementia without Alzheimer pathology. Can J Neurol Sc 1986;13:462-70.

6 Delisle MB, Gorce P, Hirsch E, et al. Motor neuron disease, parkinsonism and dementia. Report of a case with diffuse Lewy body-like intracytoplasmic inclusions. Acta Neuropathol (Berl) 1987;75:104-8.

7 Dickson DW, Davies P, Mayeux R, et al. Diffuse Lewy body disease. Neuropathological and biochemical studies of sixe patients. Acta Neuropathol (Berl) 1987;75:8-15.

8 Eggertson DE, Sima AAF. Dementia with cerebral Lewy bodies A mesocortical dopaminergic defect? Arch Neurol 1986;43 524-7.

9 Forno LS, Barbour PJ, Norville RL. Presenile dementia with Lewy bodies and neurofibrillary tangles. Arch Neurol 1978;35:818-22.

10 Gibb WRG, Esiri MM, Lees AJ. Clinical and pathologicaf features of diffuse cortical Lewy body disease (Lewy body dementia). Brain 1987;110:1131-53.

11 Ikeda K, Ikeda S, Yoshimura T, et al. Idiopathic parkinsonism with Lewy-type inclusions in the cerebral cortex: a case report. Acta Neuropathol (Berl) 1978;41:165-8.

12 Ikeda K, Hori A, Bode G. Progressive dementia with 'diffuse Lewy-type inclusions' in cerebral cortex. A case report. Arch Psychiat Nervenkr 1980;228:243-8.

13 Itoh T, Momma Y, Ogasawara N. An electron microscopic study on atypical presenile dementia with numerous Lewy bodies in the cerebral cortex. Folia Psychiat Neurol Japan 1982;36: 99-106.

14 Kayano T, Funada N, Okeda R, et al. An autopsy case of Parkinson's disease with dementia and a wide distribution of Lewy-like bodies in cerebral cortex. Neuropathology (Tokyo) 1980;1:27-28.

15 Kono $C$, Matsubara $M$, Inagaki $T$. Idiopathic orthostatic hypotension with numerous Lewy bodies in the sympathetic ganglia. Report of a case. Neurol Med Japan 1976;4:568-70.

16 Kosaka K, Shibayama H, Kobayashi H, et al. An autopsy case of unclassifiable presenile dementia. Psychiatr Neurol Japan 1973;75:18-34.

17 Kosaka K, Oyanagi S, Matsushita M, et al. Presenile dementia with Alzheimer-, Pick-, and Lewy-body changes. Acta Neuropathol (Berl) 1976;36:221-33.

18 Kosaka K. Lewy bodies in cerebral cortex. Report of three cases. Acta Neuropathol (Berl) 1978;42:127-34.

19 Kosaka K, Mehraein P. Dementia-Parkinsonism syndrome with 
Diffuse Lewy body disease: clinical features in 15 cases numerous Lewy bodies and senile plaques in the cerebral cortex. Arch Psychiat Nervenkr 1979;226:241-50.

20 Kosaka K, Yoshimura M, Ikeda K, Budka H. Diffuse Lewy body disease: progressive dementia with abundant cortical Lewy bodies and senile changes of varying degree-a new disease? Clin Neuropathol 1984;3:185-92.

21 Kuyama K, Kuroda S, Otsuki S, et al. An autopsy case of "Lewy body disease" presenting dementia. Clin Neurol (Tokyo) 1987;27:94-98.

22 Kuroda S, Hosokawa K, Iguchi K, Tateishi J. An autopsy case of presenile dementia with numerous Lewy bodies in the cerebral cortex. Clin Neurol (Tokyo) 1978;18:346-50.

23 Minagawa M, Maeshiro N, Taguchi K, Shioda A. An autopsy case showing dementia and Shy-Drager syndrome with Lewy bodies and spheroids in the substantia nigra and senile plaques in the cerebral cortex. Neuropathology (Tokyo) 1980;1:28-29.

24 Mitsuyama Y, Fukanaga H, Yamashita M. Alzheimer's disease with widespread presence of Lewy bodies. Folia Psychiatr Neurol Japan 1984;38:81-88.

25 Okazaki H, Lipkin LE, Aronson SM. Diffuse intracytoplasmic ganglionic inclusions (Lewy type) associated with progressive dementia and quadriparesis in flexion. $J$ Neuropathol Exp Neurol 1961;20:237-44.

26 Okeda R, Kayano T, Funata N, et al. An autopsy case of Parkinson's disease associated clinically with dementia terminating in akinetic mutism and pathologically with multiple Lewy bodies in the cerebral cortex. Brain Nerve (Tokyo) 1982;34:761-7.

27 Philpot M, Colgan J, Janota I, Levy R. Dementia without Alzheimer pathology. Neurology 1986;36:133.

28 Reyes PF, Suarez M, Golden G, Fariello R. Three cases of Alzheimer's disease with diffuse Lewy bodies: clinical and neuropathologic studies. Neurology 1987;37 (Suppl. 1):226.

29 Sima AAF, Clark AW, Sternberger NA, Sternberger LA. Lewy body dementia without Alzheimer changes. Can J Neurol Sci 1986;13:490-97.

30 Yagishita S, Itoh Y, Amano N, Nakano T. Atypical senile dementia with widespread Lewy type inclusion in the cerebral cortex. Acta Neuropathol (Berl) 1980;49:187-91.

31 Yoshimura $\mathbf{M}$, Shimada $\mathbf{H}$, Nagura H, Tomonaga $M$. Two autopsy cases of Parkinson's disease with Shy-Drager syndrome. Trans Soc Pathol Jap 1980;69:432.

32 Yoshimura M. Cortical changes in parkinsonian brain: a contribution to the delineation of "diffuse Lewy body disease". J Neurol 1983;229:17-32.

33 Cross RB. Demonstration of neurofibrillary tangles in paraffin sections: a quick and simple method using a modification of Palmgren's method. Med Lab Sci 1982;39:67-69.

34 Lowe J, Blanchard A, Morrell K, et al. Ubiquitin is a component of intermediate filament inclusion bodies of diverse type in man, including those of Parkinson's disease, Pick's disease, and Alzheimer's disease, as well as Rosenthal fibres in cerebellar astrocytomas, cytoplasmic bodies in muscle and Mallory bodies in alcoholic liver disease. J Pathol 1988;155:9-15.

35 Goldman JE, Yen S-H, Chiu F-C, Peress NS. Lewy bodies of Parkinson's disease contain neurofilament antigens. Science 1983;221:1082-4.

36 Wooten GF. Pharmacokinetics of levodopa. In: Marsden CD, Fahn S, eds. Movement Disorders 2. London: Butterworths. 1987:231-48.

37 Tiller-Borcich JK, Forno LS. A case of Parkinson's disease and dementia with cortical intraneuronal inclusions: Pick bodies or Lewy bodies? J Neuropathol Exp Neurol 1986;45:348.

38 Godwin-Austen RB, Lowe JS. The two types of Parkinson's disease. In: Clifford Rose F, ed. Parkinson's Disease: Clinical and Experimental Advances. London: John Libbey. 1987:79-82.

39 Marsden CD, Fahn S. Problems in Parkinson's disease and other akinetic-rigid syndromes. In: Marsden CD, Fahn S, eds. Movement Disorders 2. London: Butterworths 1987:65-72.

40 Woodard JS. Concentric hyaline inclusion body formation in mental disease: analysis in twenty-seven cases. J Neuropathol Exp Neurol 1962;21:442-9.

41 Pearce J. The extrapyramidal disorder of Alzheimer's disease. Eur Neurol 1974;12:94-103.

42 Ditter SM, Mirra SS. Neuropathologic and clinical features of Parkinson's disease in Alzheimer's disease patients. Neurology' 1987;37:754-60.

43 Stern Y, Mayeux R, Sano M, et al. Predictors of disease course in patients with probable Alzheimer's disease. Neurology 1987;37:1649-53. 